\title{
Correction to: A novel compact fractal UWB antenna with dual band notched characteristics
}

\author{
V. N. Koteswara Rao Devana ${ }^{1}$ (D) Vella Satyanarayana ${ }^{2}$ A. Vijaya Lakshmi ${ }^{3} \cdot$ Y. Sukanya $^{4} \cdot$ \\ Ch. Manohar Kumar ${ }^{5}$ V. L. N. Phani Ponnapalli ${ }^{6} \cdot K^{2}$ ili Jagadeesh Babu ${ }^{1}$
}

Published online: 8 December 2021

(C) Springer Science+Business Media, LLC, part of Springer Nature 2021

\section{Correction to: Analog Integrated Circuits and Signal Processing https://doi.org/10. 1007/s10470-021-01958-0}

The original version of this article unfortunately contained a mistake. The below author affiliations were missing in this article.

Vella Satyanarayana, ECE Department, Aditya Engineering College, A.P., India

Vijaya Lakshmi, ECE Department, Vardhaman College of Engineering, Telangana, India

Y. Sukanya, ECE Department, Vignan's Institute of Information Technology, Duvvada, India
Ch. Manohar Kumar, ECE Department, Gayatri Vidya Parishad College for Degree and PG Courses, A.P., India V. L. N. Phani Ponnapalli, ECE Department, VIKAS College of Engineering \& Technology, Vijayawada, India Kamili Jagadeesh Babu, ECE Department, St. Ann's College of Engineering \& Technology, Chirala, India

The original article has been corrected.

Publisher's Note Springer Nature remains neutral with regard to jurisdictional claims in published maps and institutional affiliations.

The original article can be found online at https:// doi.org/10.1007/s10470-021-01958-0.

V. N. Koteswara Rao Devana

dvnkrao@gmail.com

1 ECE Department, St. Ann's College of Engineering \& Technology (SACET), Chirala, India

2 ECE Department, Aditya Engineering College, Surampalem, A.P., India

3 ECE Department, Vardhaman College of Engineering, Hyderabad, Telangana, India

4 ECE Department, Vignan's Institute of Information Technology, Duvvada, India

5 ECE Department, Gayatri Vidya Parishad College for Degree and PG Courses, Visakhapatnam, A.P., India

6 ECE Department, VIKAS College of Engineering \& Technology, Vijayawada, India 